As these cases in young babies differ materially from the purulent joint diseases of later life, is it not probable that they may be due to anatomical conditions not existing at an older age?

(To be continued.)

SOME OBSERVATIONS ON CHRONIC VESICULITIS, WITH REPORT OF FOUR CASES.

$$
\text { BY J. M. THOMPson, A.B., M.D., Bostow. }
$$

Within the past few months a not inconsiderable amount of attention has been paid to inflammation of the seminal vesicles; and among the comparatively small number of writers upon the subject must be mentioned the name of Dr. Eugene Fuller of New York, whose recent contributions in this particular field of genito-urinary literature have undoubtedly proved of greatest interest.

It seems noticeably strange that in such commonly occurring lesions as those of the sexual organs, all the works pertaining to the subject should have either disregarded diseases of the vesicles as of mivor importance, or, as it would appear, have been loth to pin fuith on any form of treatment teuding to an alleviation of their most self-evident symptoms and disastrous results.

In view of the facts, it is safe to assume that vesiculitis has been regarded in the light of a necessarily accompanying symptom of certain forms of posterior urethritis, or perhape of prostatitis, and to separate it from the latter as a disease entirely distinct in itself is a matier of no grave concern. Yet, notwithstanding all this, we have come to look upon vesiculitis as something mere than a symptom - as something more than a mere form of neurasthenia existing principally in the mind of the patient. It caunot be denied, however, that the nervous phenomena associated with diseases of the male generative organs are unreasonably prominent, more especially when the sexual vigor has begun to be impaired; but, inasmuch as this is the case (and perhaps always will be), we are the more obliged to seek some means afforded for the relief of such phenomena. To that end it is highly important that a positive diagnosis be made of what to my mind is the essential factor in causing impairment - and sometimes loss - of sexual vigor, namely, seminal vesiculitis; and, what is no less important, to find the proper and most efficient means at our disposal for checking and removing that cause.

The method that is now being suggested, and the one adopted by the writer in such cases is called "stripping," another name for massage (though not strictly speaking), a term that will serve admirably to convey a clearer notion of what is meant to the mind of the reader.

Thus far, unfortunately, my experience with the method has been somewhat limited; yet $I$ feel safe in asserting that it is the treatment par excellence for all simple inflammations of the vesicles, except where there is a tubercular, or possibly syphilitic, element present, in which latter cases, of course, specific measures would be more appropriately indicated.

Before entering upon a description of the treatment, it will not be out of place to give a clinical picture of a fairly typical case of seminal vesiculitis :

First of all, the patient generally, though not always, gives a history of chronic urethral discharge lasting from a few months to several years, and for which every known remedy almost has been tried and found wanting. His neurasthenic symptoms are quite pronounced. He tells you that he notices an escape of semen during micturition, and very frequently while at stool. At times he experiences some difficulty in passing urine, and has a sensation of fulness and discomfort about the bladder and rectum. $\mathrm{He}$ is alarmed about losing his sexual vigor, and has frequent nocturnal emissions. In short, you find him a picture of mental depression and of general nervous impairment. Physical examination reveals a somewhat shrunken, anemic penis; there is a varying degree of prostatic hyperesthesia, with some or no enlargement, while one or both vesicles are enlarged, indurated and tender, and the peri-vesicular tissues in cases of long standiug are flabby and redundant. The discharge is generally a gelatinous, semen-like fluid, and if examined microscopically, will be found to contain pus, mucus, deep urethral cells and dead spermatozoa.

During treatment the patient stands, and, beuding forward, assumes a position similar to that taken in the game of "leap frog," while the operator, sitting on a chair behind him, passes into the rectum the forefinger of the hand corresponding to the vesicle that is to be stripped. At first, considerable difficulty may be experienced in reaching the vesicles; but if firm, steady pressure is used with the other three fingers against the buttock in the direction of the rectum, and at the same time the knee presses the elbow inward and upward, a vast amount of advantage cau be gained. The arm not in use may be passed around the patient's thighs and thus - if nothing moresome support obtained.

By following these suggestions, the vesicles may be easily stroked for a few minutes without any discomfort to the patient. During this manceuvre, it is well to have a glass slide or other receptacle under the meatus in order to catch whatever escapes, and as a means of obtaining fresh material for examination.

This treatment is repeated every five to seven days according to the effect produced. It has been my custom in those cases where much relaxation of the parts is present to suggest copious rectal douches of cold water daily as an efficient adjuvant to the strippiug. These can be taken either with a recurrent nozzle similar in construction to Kiefer's urethal nozzle, or with what serves the purpose equally well, the ordinary bulb syringe, in which case the patient retains in a recumbent position a few ounces of the water.

The treatment of stripping for inflammation of the seminal vesicles is as yet in its infancy, aud naturally, one must be guarded in making statements too positive as to its general etficiency; however, my experience warrants me in stating that it will be difficult to find another method that is so cheerfully accepted by the patient, or one that is likely to have such a wholesome effect upon his mental condition - a factor of no trivial significance, and, undoubtedly, one of the most stubborn to relieve.

It is needless to add that the patient must abstain assiduously from alcoholic and venereal excesses, pay strict attention to diet and hygiene, and have firmly impressed in his mind the truth of that old adage, Mens sana in corpore sano.

'The following are the only cases of which anything 
like a complete or satisfactory history can be given. It is hoped that in another paper more varied aud interesting cases may be reported:

CASE I. 'Thirty-two years old; had gonorrhea several years ago. Habits generally temperate, except that he has indulged excessively in sexual intercourse for the past two years. During the last nine months has noticed some increasing difficulty during micturition, accompanied by an uncomfortable feeling about the rectum and bladder. There has been a constant discharge from the urethra for the last four months, and an entire absence of erection. Patient's nervous system was extremely debilitated, mental depression markedly pronounced. His sleep has been generally disturbed and nocturnal emissions frequent. The discharge appeared muco-purulent and contained pus, mucus and dead spermatozoa; while the urine was heavily charged with amorphous urates. The urethra was explored, and nothing found sufficient to cause such a profuse discharge. The deep urethra, however, was very sensitive, even the passing of a flexible bougie being almost unbearable. On rectal examination, the vesicles proved to be the seat of the trouble. Both of them were slightly enlarged and teuder to touch, while the prostate remained intact. Cold steel sounds were passed about every fifth day for a few wteks, but although they had a salutary effect upon the nervous system, they did not seem to affect the discharge. The prognosis looked unfavorable till gentle stripping was tried. After the first sitting, a diminution in the amount and character of the discharge was noticeable. After three months' treatment the discharge was absent, the uritie normal in every way, and the nervous system remarkably improved. The patient was advised to spend the summer in the country, and when last heard from, considered himself in good vigorous condition.

Case II. Thirty-two years old, remarkably strong, muscular and well developed. First attack of gonorrhea was in 1879. Since that time has bad several other attacks, two of which were complicated with double epididymitis. For the last fifteen years has indulged at times in alcoholic and venereal excesses, even to the extent of occasional debauches. Beside a progressive decline in sexuai vigor for the past eight months, there has been present a thin, milky aischarge - very profuse when at stool and after excesses. There was no disturbauce during micturition. Strange to relate, in connection with these symptoms, the patient had all the characteristic symptoms of tapeworm, of which he was quite unawares. 'The penis was very small and shrunken. There was a balanic hypospadias, but nothing in the urethra to account for his condition. Examination per rectum showed the vesicles to be moderately enlarged and very slightly tender, while the peri-vesicular region was flabby. Pressure on the vesicles ejected about a teaspoonful of fluid, which contained pus, caudate epithelium, mucus, some live and many dead spermatozoa. It was thought advisable to get rid of the tenia before proceeding to the stripping. Accordingly the patient was ordered a vermifuge, which did its work in every way satisfactorily. In a week the patient came back relieved both in mind and body, but his discharge was still preseut and no change had been observed in his sexual vigor. Stripping was now begun, and continued every week for two months till the discharge had entirely ceased, and sexual vigor improved. No examination for spermatozoa has been made receutly; but without doubt, if the patient continues to lead a temperate life, his quoudam vigor will be partly restored. Despite his age and excellent physical condition, I question very seriously, in view of his history, whether he can ever possess potent sexual organs.

CASE III. Forty-eight years old; married in 1878 . During the first two years of married life two wellnourished children were born. For the last fourteen years has not lived with his wife, but has been during this period a victim of self-abuse. He had never had venereal disease. Eleven years ago noticed a decline in sexual vigor. At his first visit, four months ago, he complained of entire absence of erection and a constant urethral discharge. Great difficulty has been found recently in starting the flow of urine, which is always turbid and milky and accompanied with more or less pain and tenesmus. At times during the past seven years has been treated with various balsanic preparations, tonics and injections, but only to find himself no better, and sometimes worse, after using them. On physical examination the penis and scrotum appeared shrunken and anemic. Both vesicles, as well as the prostate, were found tender, enlarged and very sensitive. The urine was very cloudy and contained clumps and shreds, while the patient, though strong and robust, was extremely nervous. The first stripping resulted in forcing through the urethra a teaspoonful of a sticky, muco-purulent fluid containing pus, epithelial cells and countless dead spermatozoa. Strip. ping was continued every seven days for four montbs, till the discharge ceased and occasional erections took place. The urine is now clear and no difficulty is experienced in voiding it. When last seen the patient was satisfied that considerable improveruent had taken place, in short, he stated that he was about well. Considering the patient's age and history, it seems doubtful if his potency will return permanently; yet extreme satisfaction is felt when he tells me that he is "cured."

CASE IV. Forty-six years of age, contracted gonorrhea eleven years ago, of which he was entirely relieved. Up to within a short time has been a victim of self-abuse, although in other respects a man of good habits. At the time of his first visit - six months ago - he complaiued of "losing semen constantly," more especially when at stool and during micturition. Seminal emissions were frequent, and his occasional erections were never permanent enough to allow coitus. Nothing was found in the urethra except prostatic hyperesthesia, almost bordering on pain when an exploratory instrument was used. In this case the left vesicle was found to be enlarged and tender, the prostate was also slightly enlarged, while the entire peri-vesicular area was very sensitive, a little pressure giving rise to much pain. The urine was generally only slightly turbid, but at times very opaque. The discharge contained little pus, mucus, dead spermatozoa and deep urethral cells. The patient was much debilitated, and very frequently became unequal to his work, though not Jaborious, on account of vervous exhaustion. Very gentle stripping was given and carried out till the discharge was nil. Though considerable improvement has taken place in the patient's general condition, and he feels very inuch eucouraged at the result, still I fear that a strumous diathesis may be lurking in the background and will manifest itself later. 
From the foregoing can be briefly drawn the following conclusions:

(1) The common causes of vesiculitis are sexual po excesses and indiscretions.

(2) Chronic urethral discharge in a certain number of cases can be traced to an inflammation of the seminal vesicles.

(3) When chronic urethral discharge is present, independent of a venereal history, it is usually the result of seminal vesiculitis.

(4) The diagnostic symptoms of seminal vesiculitis are impaired sexual function, intermittent or constant urethral discharge (and when not present can be ejected by stripping the vesicles) containing pus, mucus, deep urethral cells, and spermatozoa - usually lifeless.

(5) 'The disease yields very satisfactorily to the treatment of stripping, which should be employed about every five to seven days, and continued according to the effect produced till the symptoms have disappeared.

(6) In every case of persistent urethral discharge I would recommend examination of the patient per rectum, and especially in the cases of so-called "spermatorrhea and impotency of the sexual organs."

(7) In the vast majority of cases of simple inflammation of the vesicles, the prognosis appears to be favorable, provided the patient adheres strictly to treatment.

(8) At the present writing, nothing further can be stated concerning tubercular inflammation of the vesicles than that it is aggravated rather than relieved by stripping, and the prognosis appears unfavorable.

\section{SOME EXPERIENCES WITH ASIATIC CHOLERA IN ASIA.}

BY M. A. JEWETT, M.D.,
United States Consul, Sivas, Turkey.

THE epidemic of cholera at Sivas, Asia Minor, seems to me to offer some points of sufficient interest to be reported.

The special points to which I would call attention are: the altitude of the place where the epidemic occurred, the manner of its dissemination, and the comparative immunity of the people under conditions most favorable for the disease.

The city of Sivas is situated on a small plateau surrounded by wountains, on the northern border of the Anti-Taurus range. It is about 5,000 feet above the sea-level. According to the general statistics of the disease this altitude should be sufficient to make Sivas safe from an epidemic of cholera; and it is true that, while cholera has frequently visited Turkey in recent years, Sivas has escaped during the past halfcentury.

It is probable that during the months of February and March there were cases of cholera here; but the cases were few, scattered, and the diagnosis was somewhat uncertain.

l think that the disease was imported from Constantinople. At least the march of cholera from Constantinople towards Sivas can be traced from town to town up to eight hours' distance (caravan time) from here.

The water of Sivas is furnished almost entirely by of the city. Situated on the banks of this river, about a mile from the city, is the village of Tavra. It has a population of about 1,000 persons. All the sewage of the village flows into the river.

On the 12th of April about twenty women came from Tavra to a Turkish bath at Sivas. The next day a dozen of them were attacked with cholera, and on the 15th of April the malady burst out in epidemic form in all quarters of Sivas. I think that the women were all infected by the same source, perhaps at the bath; but however that may be, it is certain that after they were taken ill and the river was contaminated by their choleraic dejections, the disease appeared simultaneonsly in all parts of the city. During the first week of the epidemic there were about 500 cases, and all sections of the city seemed to be about equally infected.

The diagnosis of cholera was not made by postmortem or microscopic examination; but the rapid dissemination of the disease, the violence of the attacks, often taking off persons of robust health in a few hours, the rice-water discharges, suppression of urine, the cramps, cyanosis and collapse, leave little doubt that the comma bacillus was present in all its glory.

The number of cases of cholera from the 15th of April, the day when the epidemic broke out, to the first of June, when it apparently disappeared, that is to say, during a period of forty-five days, was according to the best calculations about 5,000 , and the number of deaths approximately 1,500 . On account of an ignorant fear of the doctors and a desire to escape the surveillance of the police charged with the isolation and disinfection of infected houses, the people concealed a large proportion of the cases and deaths from the authorities, and consequently the official statistics are far from accurate.

The number of cases and deaths given above gives a mortality of thirty per cent. This relatively moderate mortality indicates that the number of mild cases was considerable, especially when one takes into consideration the conditions favorable for the disease and entirely unfavorable for the treatment of the sick, which exists in the cities of Asia Minor.

The proportion of the number of cases to the population is about twelve per cent., and that of the number of deaths about three and a half per cent. We have no statistics relative to the sex or age of the patients; but according to my opinion women were attacked in greater number than men, and the number of children affected was relatively small.

Few places are better conditioned to demonstrate that Asiatic cholera is not contagious than an Asiatic city like Sivas, and that to have the disease one must have some individual predisposition, some unknown factar. The houses are, as a rule, small, low, damp, crowded, little ventilated, poorly lighted, and for the most part built of mud. The most elementary principles of hygiene are unknown here, or when inculcated are generally disregarded. The Turk is a supreme fatalist, and he places more reliance upon a bit of the Koran pasted over his gate to keep away the disease than upon the most scientific prophylactic measures. The water which the people drink and use for all purposes about the house, flows in open ditches where the people also bathe, and wash their soiled clothing and carpets. That which has served one family for its various needs, flows with all its filth to 